\title{
ВПЛИВ $\gamma$-ОПРОМІНЕННЯ НА ПОЧАТКОВУ МАГНІТНУ ПРОНИКНІСТЬ АМОРФНИХ І НАНОКРИСТАЛІЧНИХ СПЛАВІВ НА ОСНОВІ СИСТЕМИ $\mathrm{Fe}-\mathrm{Si}-\mathrm{B}$
}

\author{
В.Ю. ПОВАРЧУК, ${ }^{1}$ В.К. НОСЕНКО, ${ }^{2}$ А.М. КРАЙЧИНСЬКИЙ, ${ }^{1}$ \\ В.Б. НЕЙМАШ, ${ }^{1}$ М.М. КРАСЬКО ${ }^{1}{ }^{1}$ В.В. МАСЛОВ ${ }^{2}$ \\ ${ }^{1}$ Інститут фізики НАН України \\ (Просn. Науки, 46, Київ 03028; e-mail: pvyи@i.ua) \\ ${ }^{2}$ Інститут металофізики ім Г. В. Курдюмова НАН України \\ (Булъв. Академіка Вернадсъкого, 36, 03680, МСП, Київ-142)
}

УДК 539.2:669:536.76

(c) 2012

\begin{abstract}
Методом визначення фактора індуктивності досліджено залежності початкової магнітної проникності $\mu_{i}$ аморфних і нанокристалічних сплавів на основі системи $\mathrm{Fe}-\mathrm{Si}-\mathrm{B}$ від дози $\gamma-$ опромінення. Виявлено, що легування аморфних сплавів системи $\mathrm{Fe}-\mathrm{Si}-\mathrm{B}$ молібденом і нікелем приводить до збільшення радіаційної чутливості їхніх $\mu_{i}$. Початкова магнітна проникність нанокристалічних сплавів на основі $\mathrm{Fe}-\mathrm{Si}-\mathrm{B}$ менш чутлива до дії $\gamma$-опромінення, ніж легованих аморфних. Висловлено припущення, що вплив радіації на початкову магнітну проникність зумовлений утворенням немагнітних включень у структурі аморфних і в аморфній матриці нанокристалічних сплавів.
\end{abstract}

\section{1. Вступ}

Аморфні і нанокристалічні сплави на основі системи $\mathrm{Fe}-\mathrm{Si}-\mathrm{B}$ характеризуються високими значеннями індукції насичення, магнітної проникності та низькими втратами на перемагнічення. Тому вони широко застосовуються у виготовленні індуктивних елементів (силових трансформаторів, малогабаритних трансформаторів, що працюють на високих частотах, дроселів) електротехнічної апаратури. 3 наукової точки зору дослідження впливу опромінення на структурно-чутливі характеристики аморфних і нанокристалічних сплавів можуть бути корисними для встановлення механізмів радіаційно-стимульованих структурних змін у таких системах. Прикладною метою нашого дослідження є вивчення доцільності застосування аморфних і нанокристалічних феромагнетиків на основі $\mathrm{Fe}-\mathrm{Si}-\mathrm{B}$ в умовах іонізуючої радіації, а також можливості керування властивостями цих матеріалів за допомогою радіаційної обробки.

3 наявних літературних даних неможливо однозначно судити про вплив $\gamma$-опромінення на магнітні властивості аморфних магнітом'яких сплавів. Автори роботи [1] повідомляють про те, що опромінення $\left(\Phi=10^{9}\right.$ рад) приводить до зростання початкової магнітної проникності $\mu_{i}$, залишкової індукції $B_{r}$, та зменшення $H_{c}$ магнітопроводів, виготовлених з магнітом'яких аморфних сплавів $\mathrm{Fe}_{85-x} \mathrm{Co}_{x} \mathrm{~B}_{15}(x=12-$ $25 \%$ ). А результати роботи [2], навпаки - свідчать про погіршення магнітних властивостей аморфних сплавів FeNiMoSiB внаслідок дії даного виду радіаційної обробки. Опромінення $\left(\Phi=10^{7} \mathrm{P}\right)$ вихідного (невідпаленого) аморфного сплаву $\mathrm{Co}_{83,5} \mathrm{Fe}_{5,5} \mathrm{Si}_{8,5} \mathrm{~B}_{2,5}$ приводить до зростання $B_{r} / B_{s}$ та $H_{c}[3]$.

Відомості про вплив $\gamma$-опромінення на магнітні властивості нанокристалічних сплавів на основі $\mathrm{Fe}-$ $\mathrm{Si}-\mathrm{B}$ нині відсутні.

Неоднозначні дані впливу $\gamma$-опромінення на магнітні характеристики аморфних сплавів зумовлюють доцільність дослідження їхніх дозових залежностей у якомога ширшому інтервалі доз. На користь цьому свідчить також немонотонний характер дозової залежності висоти першого максимуму структурного фактора [4].

\section{2. Матеріали, методи їх отримання та дослідження}

$\mathrm{Y}$ роботі досліджено вплив гамма-опромінення (джерело випромінювання $-{ }^{60} \mathrm{Co}, E_{\gamma}=1,17$ та $1,33 \mathrm{MeB}$, густина потоку $\left.\phi_{\gamma} \approx 10^{11} \gamma_{\mathrm{кв}} /\left(\mathrm{cm}^{2} \mathrm{c}^{1}\right)\right)$ дозами до $5,7 \cdot 10^{18} \mathrm{~cm}^{-2}=3,4 \cdot 10^{9}$ рад на початкову магнітну проникність аморфних сплавів типу Metglas (MGсплави) та нанокристалічних типу Finemet (FMсплави). Хімічні склади MG-сплавів наведено у табл. 1, а FM-сплавів - у табл. 2. 3 табл. 1 видно, що за концентрацією неметалевих компонент MG-сплави можна поділити на дві групи (базові системи) - $\mathrm{Fe}-$ $\mathrm{Si}_{6} \mathrm{~B}_{14}$ (MG-1 - MG-3) i Fe-Si $\mathrm{B}_{16}$ (MG-5 - MG-8). Bci 
сплави, крім MG-1 і MG-5, леговані атомами Ni та Мо. Легування MG-сплавів цими атомами підвищує їх термічну стабільність та покращує магнітні властивості [5].

Для виготовлення вихідних сплавів використовували компоненти високої чистоти: $\mathrm{Fe}-99,96$ мас.\%, $\mathrm{Si}-99,999$ мас.\%, $\mathrm{B}$ - 99,9 мас.\%, $\mathrm{Ni} \geq 99,9$ мас.\%, $\mathrm{Mo} \geq 99,8$ мас.\%, $\mathrm{Cu} \geq 99,9$ мас. $\%, \mathrm{Nb} \geq 99,9$ мас.\%, Со $\geq 99,9$ мас.\%. Один сплав (MG-3T) виготовляли 3 компонентів технічної чистоти: $\mathrm{Fe} \geq 98,6$ мас.\%, Мо $\geq 99$ мас.\%, феробор ФБ-17 (В $\approx 20,5$ мас.\%, $\mathrm{Al}-1,2 \%, \mathrm{Si}-0,4 \%)$, феронікель $\Phi \mathrm{H}-5(\mathrm{Ni}-7,8$ мac. $\%, \mathrm{Co}-0,36 \%, \mathrm{Cu}-0,11 \%, \mathrm{Al}-0,1 \%, \mathrm{Si}-$ $0,03 \%)$.

Сплави виготовляли в індукційній печі в інертній атмосфері Ar. Хімічний склад сплавів визначали методом флуоресцентного рентгенівського аналізу. Аморфні стрічки шириною 10 мм та товщиною 24-26 мкм отримано методом спінінгування розплаву на повітрі на установці відкритого типу.

Для дослідження магнітних властивостей аморфних і нанокристалічних сплавів із вихідної (невідпаленої) аморфної стрічки виготовляли магнітопроводи (кільцеві осердя) за допомогою спеціального обладнання для намотування 3 мінімальним натягом. Геометричні параметри витих кільцевих осердь зразків становили 12·20/10 (внутрішній діаметр·зовнішній діаметр/висота, мм). Магнітопроводи, виготовлені 3 MG-сплавів, відпалювали при температурі $420{ }^{\circ} \mathrm{C}$ протягом 15 хв в атмосфері вуглекислого газу. Відпал осердь, виготовлених зі сплавів FM-6, FM-10 та FM-11 здійснювали в атмосфеpi вуглекислого газу при температурі $T=520{ }^{\circ} \mathrm{C}$ протягом $30 \mathrm{xв}$, а сплаву FM-2T - при $T=535{ }^{\circ} \mathrm{C}$ протягом 60 хв. Для вимірювання початкової магнітної проникності $\left(H_{m}=0,2 \mathrm{~A} / \mathrm{m}, f=10 \mathrm{i}\right.$ 100 кГц) використовували метод визначення фактора індуктивності [6]. Точність визначення $\mu_{i}$ становить $5 \%$.

Т а б ли ц я 1. Хімічний склад (ат. \%) аморфних сплавів типу Metglas

\begin{tabular}{c|c|c|c|c|c|c}
\hline № & Сплав & $\mathrm{Fe}$ & $\mathrm{Si}$ & $\mathrm{B}$ & $\mathrm{Ni}$ & Mо \\
\hline 1 & MG-1 & 80 & 6 & 14 & & \\
2 & MG-2 & 76,2 & 6 & 14 & 3,8 & \\
3 & MG-3T & 78,5 & 6 & 14 & 1 & 0,5 \\
4 & MG-5 & 82 & 2 & 16 & & \\
5 & MG-6 & 78 & 2 & 16 & 1 & 3 \\
6 & MG-7 & 77,5 & 2 & 16 & 3,5 & 1 \\
7 & MG-8 & 75,5 & 2 & 16 & 3,5 & 3 \\
\hline
\end{tabular}

\section{3. Експериментальні результати та їх обговорення}

Термообробка MG-сплавів приводить до збільшення (у кілька разів) початкової магнітної проникності $\mu_{i}$, зменшення коерцитивної сили $H_{c}$, петля гістерезису стає вужчою та зменшується кількість стрибків Баркгаузена. Це пов'язується зі зменшенням магнітної анізотропії внаслідок зняття внутрішніх напружень [7]. Такі сплави знаходять широке застосування у промисловості. Їхньою найбільш структурно-чутливою магнітною характеристикою є початкова магнітна проникність $\mu_{i}$. У роботі наведено результати дослідження впливу опромінення саме на цю характеристику магнітопроводів, відпалених в оптимальному режимі.

Як видно з рис. 1, радіація не впливає на початкову магнітну проникність нелегованих сплавів MG-1 i MG-5. У легованих нікелем і молібденом MG-сплавах спостерігається зменшення $\mu_{i}$ зі збільшенням дози $\gamma$ опромінення. Найбільші відносні зміни $\mu_{i}$ спостерігаються для сплавів MG-6 і MG-8 (28\% і 23\% відповідно), в яких концентрація Ni становить, відповідно, 1 i $3,5 \%$, a Mo - 3\%. Для сплаву MG-7, в якому концентрація Ni становить $3,5 \%$, а Mo - $1 \%$, відносні зміни $\mu_{i}$ становлять близько $20 \%$. Незначне зменшення початкової магнітної проникності спостерігається у сплаві MG-2, який містить $3,8 \%$ Ni i не містить Мо. Таким чином, зменшення початкової магнітної проникності досліджуваних MG-сплавів під дією $\gamma$-опромінення може бути пов'язане, перш за все, з наявністю в їхньому хімічному складі атомів Мо.

Динаміка змін залежності початкової магнітної проникності сплаву MG-3T, виготовленого з компонент технічної чистоти, під дією опромінення дещо відрізняється (рис. 1,a). Очевидно, суттєву роль відіграють домішки, що входять до його складу.

У роботі [4] показано, що легування нікелем і молібденом аморфних сплавів $\mathrm{Fe}-\mathrm{Si}-\mathrm{B}$ приводить до зменшення чутливості до дії опромінення їхніх структурних факторів $i(s)$. Це свідчить про те, що принаймні у легованих MG-сплавах вплив опромінення на структурно-чутливі магнітні характеристики не пов'язаний зі зміною інтегральних параметрів ближньо-

Т а б л и ц я 2. Хімічний склад (ат. \%) нанокристалічних сплавів типу Finemet

\begin{tabular}{c|c|c|c|c|c|c|c}
\hline № & Сплав & $\mathrm{Fe}$ & $\mathrm{Si}$ & $\mathrm{B}$ & $\mathrm{Cu}$ & $\mathrm{Nb}$ & $\mathrm{Co}$ \\
\hline 1 & FM-2T & 73 & 15,8 & 7,2 & 1 & 3 & \\
2 & FM-6 & 73,6 & 15,8 & 7,2 & 1 & 2,4 & \\
3 & FM-10 & 71,25 & 16,4 & 7,7 & 1 & 2,1 & 1,55 \\
4 & FM-11 & 70,05 & 16,4 & 9 & 1 & 2 & 1,55 \\
\hline
\end{tabular}



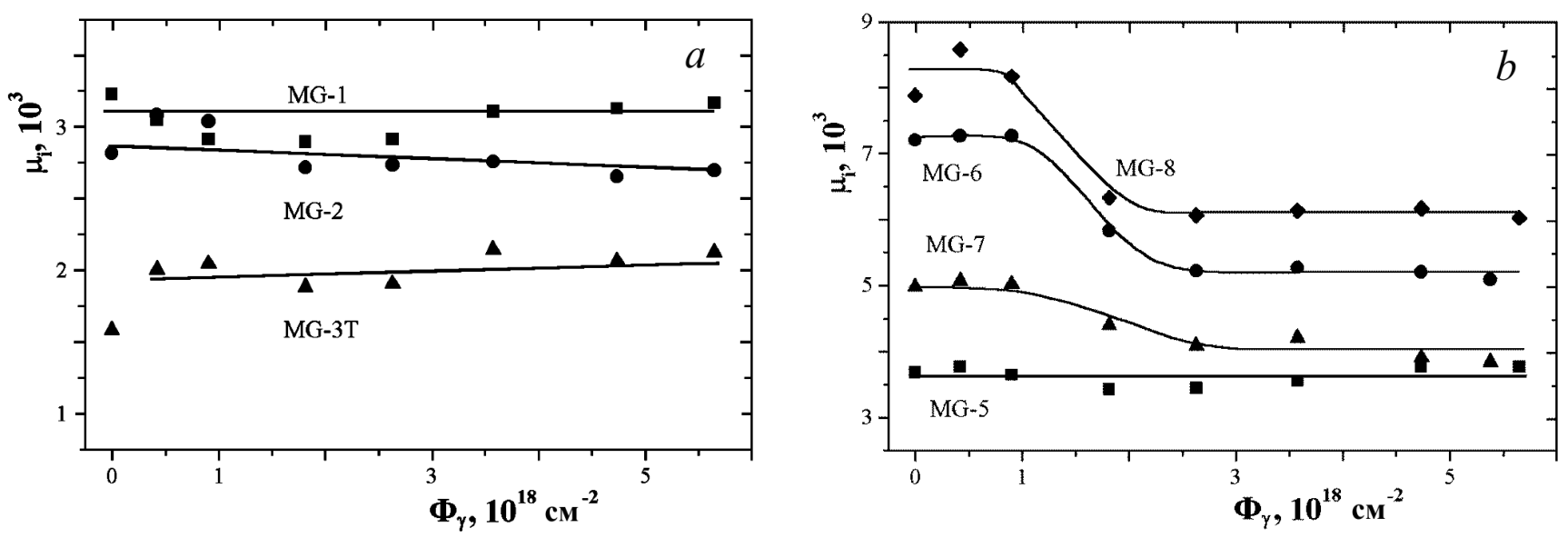

Рис. 1. Дозові залежності початкової магнітної проникності ( $f=10$ кГц) магнітопроводів, виготовлених з МG-сплавів

го порядку. Зважаючи на залежність радіаційностимульованих змін початкової магнітної проникності MG-сплавів від концентрації легуючих компонент, можна припустити, що опромінення приводить до утворення кластерів, в яких присутній, перш за все, молібден, а також атоми найбільш рухливих компонент сплаву - B i/або Si. Поява таких немагнітних включень може приводити до зниження рухливості доменних стінок [8]. Можливість їх утворення підтверджується авторами робіт [9, 10]. Збагачені молібденом області утворюються у приповерхневому шаpi аморфних металевих сплавів (АМС). Автори робіт [11-17] вважають, що поверхня боромістких АMC збагачується також атомами бору, особливо вільна сторона (при виготовленні сплаву не контактує з поверхнею диска) стрічок $[11,12]$. Підвищена концентрація атомів цього елемента на поверхні AMC спостерігається не лише у вихідних аморфних стрічках, але й у термооброблених [13-17]. Термообробка приводить до додаткового підвищення концентрації бору у приповерхневих шарах ( $\approx 50 \AA)$ стрічок [13]. Таким чином, утворення кластерів, що містять молібден і бор, під дією опромінення слід очікувати у приповерхневих шарах стрічки. Незмінність початкової магнітної проникності сплавів $\mathrm{Fe}-\mathrm{Si}-\mathrm{B}$ в інтервалі доз опромінення вищих за $2,5 \cdot 10^{18} \gamma_{\text {кв }} / \mathrm{cm}^{2}$ можна пояснити насиченням хімічних зв'язків атомів Мо з атомами неметалевих елементів.

Для встановлення основних механізмів впливу $\gamma$ опромінення на структуру та магнітні властивості нелегованих сплавів системи $\mathrm{Fe}-\mathrm{Si}-\mathrm{B}$ необхідні додаткові дослідження.

На рис. 2 наведено залежності початкової магнітної проникності нанокристалічних сплавів від дози $\gamma$-опромінення. Порівнюючи дані з рис. 1 і 2 , приходимо до висновку, що $\mu_{i}$ FM-сплавів менш чутлива до дії опромінення, ніж легованих молібденом і нікелем MG-сплавів. Максимальні зміни початкової магнітної проникності, зумовлені опроміненням сплаву FM-2T, становлять $12 \%$, a FM-6tn (tn - тонша стрічка (24 мкм)) та FM-6tc (tc - товща стрічка (38 мкм)) приблизно $8 \%$ і $12 \%$ (рис. 2,a). Для магнітопроводів, виготовлених зі сплавів FM-10 та FM-11, що мають у своєму складі Со, зменшення $\mu_{i}$ не перевищує, відповідно, $5 \%$ і $7 \%$ (рис. 2,b).

Нанокристалічні сплави типу Finemet $є$ двофазною системою, в якій і кристалічна, і аморфна фази при кімнатній температурі феромагнітні. Об'ємна частка кристалічної фази в FM-сплавах становить близько $70 \%$, а склад нанозерен оцінюється як $\mathrm{Fe}-\mathrm{Si}(18-23$ ат.\%) [18-20]. Інші елементи, що входять до складу FM-сплавів, практично нерозчинні в $\alpha$-Fe( $\mathrm{Si})$, тому знаходяться в аморфній матриці. Загалом, зміни початкової магнітної проникності FM-сплавів, зумовлені дією $\gamma$-опромінення, можуть бути пов'язані з атомними перебудовами в аморфній матриці сплавів, у кристалічній та на границях кристалів. Однак відчутні зміни початкової магнітної проникності кристалічних матеріалів можна виявити при значно вищих дозах $\gamma$-опромінення. Це підтверджують наші дослідження впливу даного виду радіації на магнітні характеристики трансформаторної сталі. Оскільки найбільш рухливий елемент сплаву - бор знаходиться в аморфній матриці, то зумовлені радіацією зміни початкової магнітної проникності можна пов'язати з його дифузією до границь кристалів або 3 його участю в утворенні немагнітних кластерів в аморфній матриці. Крім того, зменшення початкової 

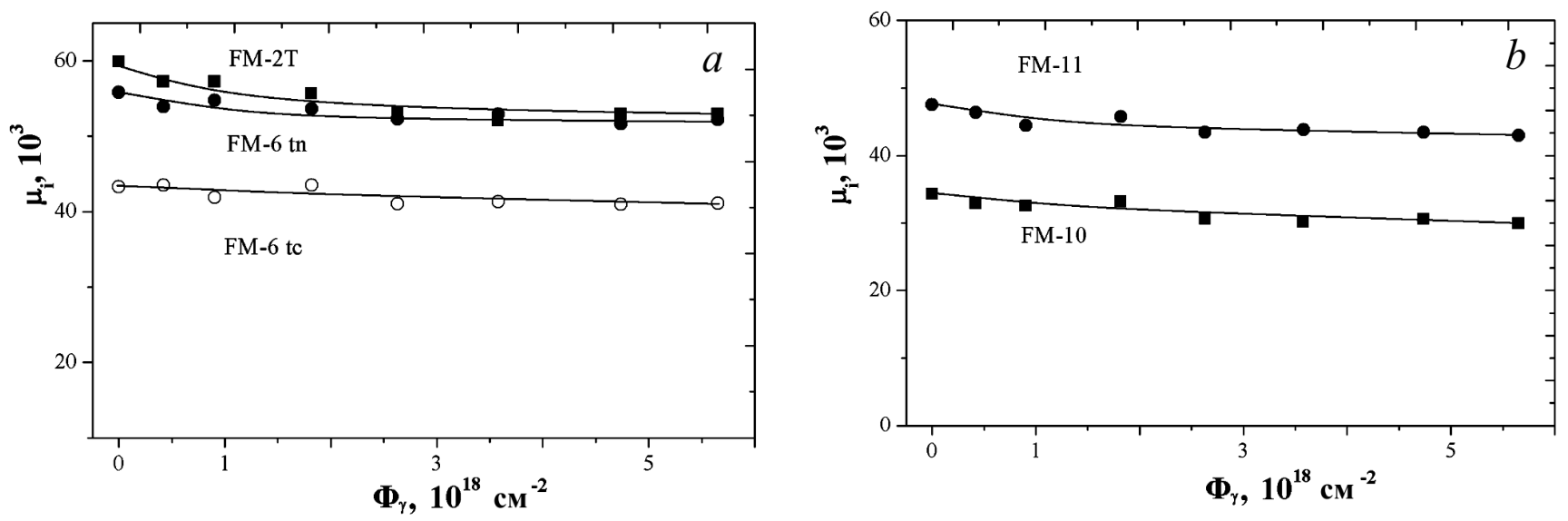

Рис. 2. Дозові залежності початкової магнітної проникності ( $f=10$ кГц) магнітопроводів, виготовлених з $\mathrm{FM-сплавів}$

магнітної проникності під дією радіації може бути зумовлене ростом кристалітів. Із літературних даних $[18,21]$ відомо, що при зростанні розмірів кристалів від 10 до 40 нм у сплавах типу Finemet їхні магнітні властивості погіршуються. Відбувається істотне (у декілька разів) зменшення $\mu_{i}$ та збільшення $H_{c}$. Однак, зважаючи на величину дози опромінення й на те, що FM-сплави є досить стабільною квазірівноважною системою (кристалічна фаза при їх термообробці виділяється за лічені хвилини, тобто протягом майже всього часу відпалу частка кристалічної фази не змінюється), цей механізм є малоймовірним. Як видно з рис. 1 і 2 , істотні зміни $\mu_{i}$ та вихід на насичення залежностей $\mu_{i}\left(\Phi_{\gamma}\right)$, легованих нікелем і молібденом MG-сплавів, а також FMсплавів, відбуваються в однакових інтервалах доз $\gamma$-опромінення. Це може свідчити про те, що зумовлені радіаційною обробкою зміни початкової магнітної проникності пов'язані зі структурними змінами в аморфній матриці FM-сплавів. Більше того, схожість дозових залежностей початкової магнітної проникності може також означати, що механізми впливу опромінення на структуру аморфної матриці FMсплавів і на структуру MG-сплавів якісно однакові. Роль, яку, ймовірно, виконує молібден у MG-сплавах, у нанокристалічних може належати атомам ніобію. Утворення немагнітних включень під дією іонізуючої радіації в FM-сплавах слід очікувати на границях кристалітів і/або в приповерхневих шарах стрічки.

\section{4. Висновки}

Таким чином, у роботі:
1. Виявлено, що легування нікелем і молібденом аморфних сплавів $\mathrm{Fe}-\mathrm{Si}-\mathrm{B}$ приводить до збільшення чутливості їхньої початкової магнітної проникності до дії опромінення. Чутливість $\mu_{i}$ зростає зі збільшенням концентрації Мо і мало залежить від концентрації $\mathrm{Ni}$.

2. Виявлено, що початкова магнітна проникність нанокристалічних сплавів на основі $\mathrm{Fe}-\mathrm{Si}-\mathrm{B}$ менш чутлива до дії $\gamma$-опромінення, ніж легованих аморфних.

3. Висловлено припущення, що вплив радіації на початкову магнітну проникність зумовлений утворенням немагнітних включень у структурі аморфних і в аморфній матриці нанокристалічних сплавів.

1. В.В. Полотнюк, Т.В Ефимова, А.М. Шалаев, В.М. Шкапа, Металлофизика 13, № 11 (1991).

2. В.В. Маслов, В.К. Носенко, В.Б. Неймаш, В.Ю. Поварчук, Металлофиз. и нов. технол. 24, №6 (2002).

3. А.М. Шалаев, В.В. Полотнюк, М.П. Круликовская, С.В. Золкина, В.В. Котов, Л.А. Олиховская, Металлофизика 6, №4 (1984).

4. В.Ю. Поварчук, В.Б. Неймаш, А.М. Крайчинський, В.К. Носенко, В.В. Маслов, Г.М. Зелінська, УФЖ 53, №10 (2008).

5. В.В. Маслов, В.К. Носенко, А.П. Бровко, Г.М. Зелинская, В.А. Машира, Металлофиз. и нов. технол. 24, №11 (2002).

6. Сердечники для катушек индуктивности и трансформаторов, используемых в аппаратуре дальней свлзи. Часть 2. Руководство по составлению технических условий - ГОСТ 29005-91 (МЕK 367-1-74) (Комитет стандартизации и метрологии СССР, Москва, 1991). 
7. К. Судзуки, Х. Фудзимори, К. Хасимото, Аморфные металль, под. ред. Ц. Масумото. Пер. с япон. Под ред. И.Б. Кекало (Металлургия, Москва, 1987).

8. С. Тикадзуми, Физика ферромагнетизма. Магнитные характеристики и практические применения, под. ред. Р.В. Писарева (Мир, Москва, 1987).

9. Л. Беднарська, М. Ковбуз, О. Білик, М. Гореча, Матеріали міжснародної конференцї̈-виставки "Проблеми корозї̈ і протикорозійного захисту матеріалів", КОРОЗІЯ-98 (9-11 червня 1998, Лъвів).

10. M. Naka, K. Hashimoto, and T. Masumoto, J. Non-Cryst. Solids 34, 355 (1979).

11. A.Z. Nagy, B. Vasvari, P. Duwez et al., Phys. Status Solidi A 61, 689 (1980).

12. J. Nagy, T. Tarnoozy, M. Hosso, and F. Pavlyak, in Proceedings of the Conference on Metallic Glasses: Science and Technology, Budapest, 1980 (Budapest, 1981), p. 223.

13. J.L. Walter, F. Bacon, and F.E. Luborsky, Mater. Sci. Eng. 24, 239 (1976).

14. Th. Berghaus, H. Neddermeyer, W. Radlik, and V. Rogge, Physica Scripta 4, 194 (1983).

15. Т.И. Братусь, М.А. Васильев, В.Т. Черепин, Металлофизика 5, №1 (1983).

16. А.В. Романова, В.В. Немошкаленко, Г.М. Зелинская и др., Металлофизика 5, №4 (1983).

17. Г.М. Зелинская, А.В. Романова, В.В. Немошкаленко и др., УФЖ 28, №9 (1983).

18. И.Б. Кекало, Нанокристаллические магнитомягкие материаль (МИСиС, Технологический университет, Москва, 2000).

19. I. Mat'ko, P. Duhaj, P. Švec, and D. Janičkovič, Mater. Sci. Eng. A 179-180, 557 (1994).

20. Е.Н. Власова, Н.Б. Дьяконова, И.В. Лясоцкий, Б.В. Молотилов, Д.Л. Дьяконов, Металлы №2 (2001).

21. Р.А. Андриевский, А.М. Глезер, Физика металлов и металловедение 88, № 1 (1999).

Одержано 29.03.11
ВЛИЯНИЕ $\gamma$-ОБЛУЧЕНИЯ НА НАЧАЛЬНУЮ

МАГНИТНУЮ ПРОНИЦАЕМОСТЬ АМОРФНЫХ И НАНОКРИСТАЛЛИЧЕСКИХ СПЛАВОВ НА ОСНОВЕ СИСТЕМЫ Fe-Si-B

В.Ю. Поварчук, В.К. Носенко, А.М. Крайчинский, В.Б. Неймаш, М.М. Красъко, В.В. Маслов

$\mathrm{P}$ е $з$ ю м е

Методом определения фактора индуктивности исследованы зависимости начальной магнитной проницаемости $\mu_{i}$ аморфных и нанокристаллических сплавов на основе системы $\mathrm{Fe}-\mathrm{Si}-\mathrm{B}$ от дозы $\gamma$-облучения. Обнаружено, что легирование аморфных и нанокристаллических сплавов системы $\mathrm{Fe}-\mathrm{Si}-\mathrm{B}$ молибденом и никелем приводит к увеличению радиационной чувствительности их $\mu_{i}$. Начальная магнитная проницаемость нанокристаллических сплавов менее чувствительна к воздействию $\gamma$-облучения, чем легированных аморфных. Сделано предположение, что влияние радиации на начальную магнитную проницаемость вызвано образованием немагнитных включений в структуре аморфных и аморфной матрице нанокристаллических сплавов.

INFLUENCE OF $\gamma$-IRRADIATION ON INITIAL MAGNETIC PERMEABILITY OF AMORPHOUS AND NANOCRYSTALLINE Fe-Si-B-BASED ALLOYS

V.Yu. Povarchuk ${ }^{1}$, V.K. Nosenko ${ }^{2}$, A.M. Kraitchinskii ${ }^{1}$, V.B. Neimash ${ }^{1}$, M.M. Kras'ko ${ }^{1}$, V.V.Maslov $^{2}$

${ }^{1}$ Institute of Physics, Nat. Acad. of Sci. of Ukraine (46, Prosp. Nauky, Kyiv 03028, Ukrain) ${ }^{2}$ G.V. Kurdyumov Institute for Metal Physics, Nat. Acad. of Sci. of Ukraine (36, Academician Vernadskyi Ave., Kyiv 03142, Ukraine)

$\mathrm{S} u \mathrm{~m}$ m a r y

By determining the inductance factor, the dependence of initial magnetic permeability $\mu_{i}$ of amorphous and nanocrystalline $\mathrm{Fe}-$ $\mathrm{Si}-\mathrm{B}$-based alloys on the $\gamma$-irradiation dose has been studied. The doping of amorphous $\mathrm{Fe}-\mathrm{Si}-\mathrm{B}$ alloys with nickel and molybdenum was found to enhance the radiation sensitivity of $\mu_{i}$. The initial magnetic permeability of nanocrystalline magnetic alloys was found to be less sensitive to the action $\gamma$-radiation than that of doped amorphous ones. A hypothesis has been put forward that the influence of radiation on the initial magnetic permeability is associated with a creation of non-magnetic inclusions in the structure of amorphous alloys and in the amorphous matrix of nanocrystalline alloys. 